\title{
Study of Concomitant Strabismus amongstthe EthnicPopulation of Manipur.
}

\author{
${ }^{1}$ Dr. Kipa Tubing, ${ }^{2}$ Dr. Thungpamo patton, ${ }^{3}$ Dr. Laishram Usharani, ${ }^{4}$ Dr. Gomi \\ Basar, ${ }^{5}$ Dr. Wobenthong Tsapoe, ${ }^{6}$ Dr. Lalhriatpuii ST, \\ ${ }^{7}$ Dr. Moiranghtem Satyabama \\ ${ }^{I}$ Post-Graduate-Trainee, Dept. of Ophthalmology, RIMS, Imphal, India. \\ ${ }^{2}$ Post-Graduate-Trainee, Dept. of Ophthalmology, RIMS. \\ ${ }^{3}$ Senior Resident, Dept. of Ophthalmology, RIMS. \\ ${ }^{4}$ Post-Graduate-Trainee, Dept. of Biochemistry, RIMS. \\ ${ }^{5}$ Post-Graduate-Trainee, Dept. of Ophthalmology, RIMS. \\ ${ }^{6}$ Post-Graduate-Trainee, Dept. of IHBT, RIMS, Imphal, India. \\ ${ }^{7}$ Professor \& Head, Dept. of Ophthalmology, RIMS.
}

\begin{abstract}
:
Objective: To find out the prevalence of concomitant strabismus among ethnic Manipuris of India and the associated refractive changes in concomitant squint.

Study design and setting: Descriptive Cross-sectional study conducted in the Outpatient Ophthalmology Department at Regional Institute of Medical Sciences (RIMS), Imphal (Manipur), for a period of two years from September 2010 to July 2012.

Methods:Complete Ophthalmological, Orthoptic and squint work-up were done for 72 strabismus diagnosed cases from Outpatient Ophthalmology Department in RIMS Hospital.

Results: The overall prevalence of strabismus was found to be $2.31 \%$ per thousand population, with a higher prevalence of exotropia (58.33\%) as compared to esotropia (41.67\%). All the patients with strabismus had associated refractive error of varying degrees, most common being hypermetropia (33.3\%), followed by myopia (22.92\%), myopic astigmatism (22.92\%) and hyperopic astigmatism (20.83\%). Thus the study showed divergent type of strabismus is more prevalent in mongoloids (Ethnic Manipuris), with hypermetropia being more commonly associated with convergent strabismus and myopia with divergent strabismus.
\end{abstract}

Key words:Strabismus, Esotropia, Exotropia,Hypermetropia, Myopia, Astigmatism.

\section{Introduction}

Strabismus is a condition in which there is a misalignment of the two visual axes so that the object of regard falls on the fovea of one eye (called the fixing eye) and on the extra foveal area of the other eye (called the deviating eye).This deviation of one eye relative to the other impairs the ability of the eye for motor and sensory fusion of images (into single binocular vision), resulting in the occurrence of two distressing phenomenon: - diplopiaand confusion ${ }^{(1)}$.Concomitant strabismus is a common ophthalmic disorder of the eyes where the angle of deviation is constant in all directions of gaze (Latin, comes- companion), Concomitant strabismus accounts for $95 \%$ of the cases of strabismus. It includes several clinical subtypes such as esotropia, exotropia, hypertropia, microtropia, and monofixation syndrome. A strong genetic background for its etiology has been suggested by twin, family, and population studies ${ }^{(2)}$. The prevalence of strabismus ranges from $3-5 \%^{(3-}$ ${ }^{4)}$,esodeviations being more common than exodeviations (prevalence ratio $\left.5: 2\right)^{(5-6)}$.However, geographical and ethnic variations in this pattern are known. Amongst esodeviations, accommodative esotropia is the commonest type followed by congenital or infantile esotropia ${ }^{(7-9)}$.The incidence varies with the age group with highest incidence of 1 to $2 \%$ occurring between 5 and 7 years of age and declining thereafter until 13 years of age ( 1 to $1.5 \%)^{(10)}$. The prevalence of strabismus in Indian population is estimated to be $3-4 \%{ }^{(11)}$.

The present study was conducted to find out the prevalence of concomitant strabismus among ethnic Manipurisand to find out the associated refractive changes of concomitant squint.

\section{Materials and methods:}

A descriptive cross sectional study was conducted among ethnic Manipuri patients attending Out Patient Ophthalmology department in Regional Institute of Medical Sciences, Imphal. Out of 72 strabismus patients a total of 60 patients diagnosed with concomitant strabismus were included in this study, of which only 48 patients participated and gave consent for this study, the remaining 7 were too young for assessment, other 5 patients were unwilling to take part in assessment and the rest 12 patients consisted of either 
incomitantstrabismus or post surgical cases. Patients with incomitant squints, e.g. Paralytic Strabismus, Restrictive Strabismus, patients with consecutive strabismus following previous Squint Corrective Surgery, and patients of Strabismus following trauma or other toxic causes were excluded. Ethical clearance was obtained from the Institutional Ethical Committee, Regional Institute of Medical Sciences, Imphal.Patient's relevant history about the ailment such as age and time of onset, chronicity, associated loss of vision, ocular injury, family history, nystagmus and diplopia were asked from the patient or his/her relative.

Complete Ophthalmological and Orthoptic work-up including - visual acuity test by Snellen's chart, refraction, stereoacuity tests, diplopia charting for noncomitant squint and prism bar cover test to measure degree of deviation, forced duction test to rule out paralytic/ restrictive component were done for each patient. Complete squint work-up including Refraction, Hirschberg's test, Krimsky's prism reflex test, eye Cover test, Cover-Uncover test and Prism Bar Cover Test (PBCT) were done for each participating patient.

\section{Results and Observations:}

Table 1: Distribution of cases according to sex and age of presentation to eye OPD

\begin{tabular}{|c|c|c|c|c|c|c|}
\hline $\begin{array}{c}\text { Age } \\
\text { group } \\
\text { (in years) }\end{array}$ & Male & Female & $\begin{array}{c}\text { Total } \\
\text { Cases }\end{array}$ & $\begin{array}{c}\text { Total } \\
\text { Percentage }\end{array}$ & $\begin{array}{c}\text { Mean } \\
\text { Age }\end{array}$ & $\begin{array}{c}\text { Standard } \\
\text { Deviation }\end{array}$ \\
\hline 0 - 6 yrs & 6 & 8 & 14 & $(29.17 \%)$ & & \\
\hline $7-12$ yrs & 10 & 7 & 17 & $(35.42 \%)$ & \multirow{2}{*}{9.6} & \multirow{2}{*}{1.60} \\
\hline $13-18$ yrs & 2 & 7 & 9 & $(18.75 \%)$ & \\
\hline $19-25$ yrs & 3 & 3 & 6 & $(12.5 \%)$ & & \\
\hline$>26$ yrs & 1 & 1 & 2 & $(4.17 \%)$ & & \\
\hline Total & 22 & 26 & 48 & $100 \%$ & & \\
\hline
\end{tabular}

Table 1 shows In that in the present study group, themaximum number of cases were found in the agegroup of 7 to 12 years comprising 17 cases $(35.42 \%)$, who participated in the detailed strabismus work-up. The average age of presentation of the study group was 12 years (range 4 year to37 years). And Male female ratio is 1.18:1.

Table 2: Distribution of cases according to types of Concomitant Squint

\begin{tabular}{|c|c|c|}
\hline Type of squint & Esotropia & Exotropia \\
\hline No of males & $7(14.58 \%)$ & $15(31.25 \%)$ \\
\hline No of females & $13(27.28 \%)$ & $13(27.28 \%)$ \\
\hline Total number of cases & $20(41.67)$ & $28(58.33 \%)$ \\
\hline
\end{tabular}

Table 2 shows out of the 48 patients, 20 cases $(41.67 \%)$ presented with convergent strabismus and 28 cases $(58.33 \%)$ presented with divergent strabismus. Male constituted 7 cases $(14.58 \%)$, and females constituted 13 cases $(27.28 \%)$ of the Convergent strabismus cases. Males constituted 15 cases $(31.25 \%)$, and the females constituted 13 cases $(27.28 \%)$ of the divergent strabismus cases.

Table 3: Distribution of cases according to type of refractive error

\begin{tabular}{|c|c|c|c|c|}
\hline $\begin{array}{c}\text { Type of refractive } \\
\text { error }\end{array}$ & Myopia & Hypermetropia & $\begin{array}{c}\text { Myopic } \\
\text { astigmatism }\end{array}$ & $\begin{array}{c}\text { Hyperopic } \\
\text { astigmatism }\end{array}$ \\
\hline No of males & 4 & 7 & 6 & 5 \\
\hline No of females & 7 & 9 & 5 & 5 \\
\hline Total no of cases & 11 & 16 & 11 & 10 \\
\hline Total Percentage & $22.92 \%$ & $33.33 \%$ & $22.92 \%$ & $20.83 \%$ \\
\hline
\end{tabular}

Table 3 shows that all the 48 cases were having refractive error associated with the strabismus out of which, 11 cases $(22.92 \%)$ were myopic, 16 cases (33.33\%) were hypermetropic, and 21 cases (43.75\%) were astigmatic. 
Fig. 1: Chart showing concomitant strabismus associated with different types of refractiveerror

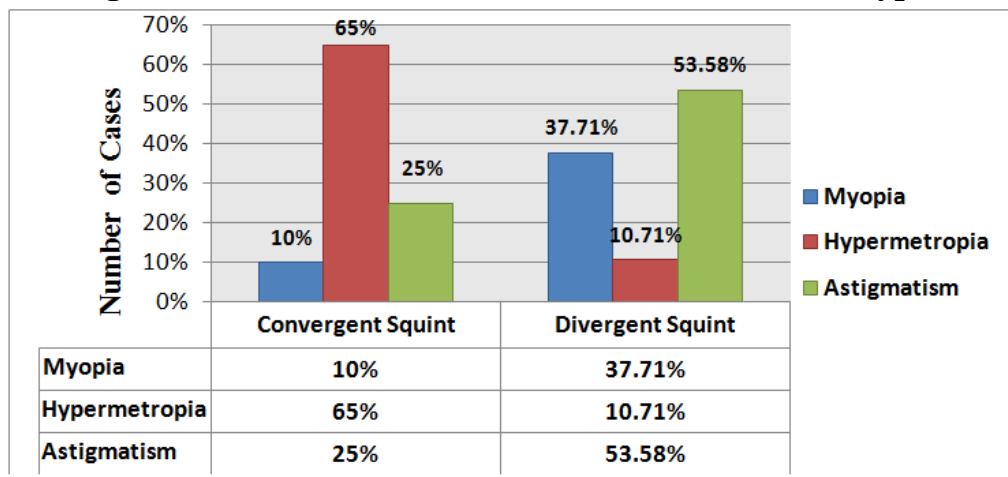

Fig. 1 shows that convergent squint was associated with 2 cases $(10 \%)$ of myopia, 13 cases $(65 \%)$ cases of Hypermetropia, and 5 cases (25\%) of astigmatism. Divergent strabismus was associated with 10 cases (35.71\%) of myopia, 3 cases $(10.71 \%)$ of Hypermetropia and 15 cases $(53.58 \%)$ of astigmatism.

Fig. 2: Chart showing association between concomitant squint and myopia

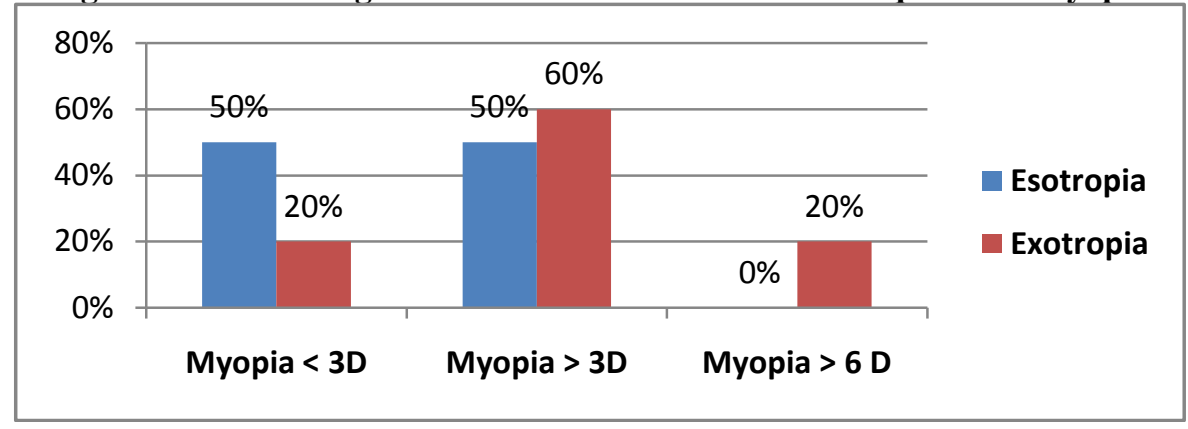

Fig. 2 shows of the 12 cases of myopia associated with concomiant strabismus, 2 myopics were associated with convergent strabismus and 10 myopics were associated with divergent strabismus.

Fig. 3: Chart showing association of concomitant strabismus with Hypermetropia

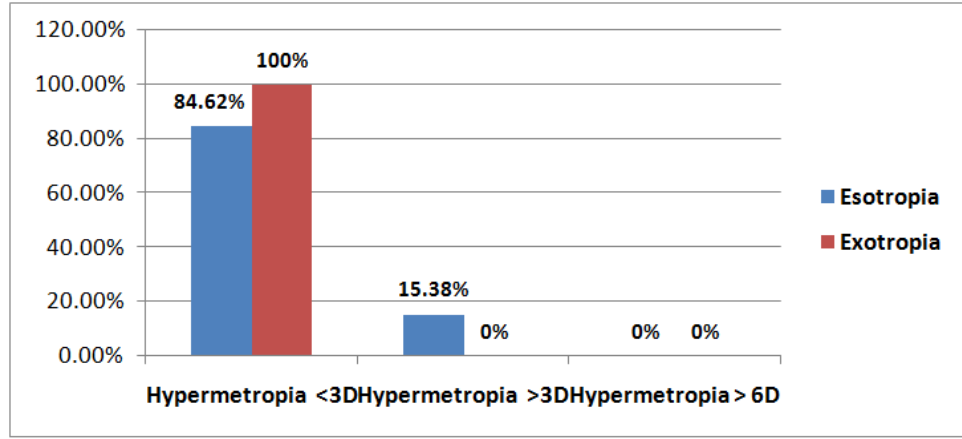

Fig. 3 shows that out of 16 cases of hypermetropics, 13 cases were associated with convergent strabismus and 3 cases were associated with divergent strabismus.

Table 4: Association between concomitant squint and astigmatism

\begin{tabular}{|c|c|c|c|c|}
\hline \multirow{2}{*}{$\begin{array}{c}\text { Degree } \\
\text { of Astigmatism }\end{array}$} & \multicolumn{2}{|c|}{ Convergent Strabismus } & \multicolumn{2}{c|}{ Divergent Strabismus } \\
\cline { 2 - 5 } & Total cases & Percentage & Total cases & Percentage \\
\hline $\begin{array}{c}\text { Myopic } \\
\text { Astigmatism <1.5D }\end{array}$ & 0 & 0 & 10 & $66.67 \%$ \\
\hline $\begin{array}{c}\text { Myopic Astigmatism> } \\
\text { 1.5D }\end{array}$ & 0 & 0 & 0 & 0 \\
\hline $\begin{array}{c}\text { Hypermetropic } \\
\text { Astigmatism <1.5D }\end{array}$ & 4 & $80 \%$ & 5 & $33.33 \%$ \\
\hline $\begin{array}{c}\text { Hypermetropic } \\
\text { Astigmatism > 1.5D }\end{array}$ & 1 & $20 \%$ & 0 & 0 \\
\hline Compound & & & & \\
\hline
\end{tabular}


Study of Concomitant Strabismus amongst the Ethnic Population of Manipur.

\begin{tabular}{|c|c|c|c|c|}
\hline Astigmatism <1.5D & 0 & 0 & 0 & 0 \\
\hline $\begin{array}{c}\text { Compound } \\
\text { Astigmatism }>1.5 \mathrm{D}\end{array}$ & 0 & 0 & 0 & 0 \\
\hline Total cases & 5 & 0 & 15 & 0 \\
\hline
\end{tabular}

Table 4 shows of the 20 cases of strabismic patients with astigmatism, 10 cases of divergent strabismus patients were associated with myopic astigmatism of $<1.5 \mathrm{D}$, and 5 cases of divergent strabismus were associated with hypermetropic astigmatism of $<1.5 \mathrm{D}$. And of the 5 cases of convergent strabismus with astigmatism, 4 cases were associated with hypermetropic astigmatism of $<1.5 \mathrm{D}$, and 1 case was associated with hypermetropic astigmatism of $>1.5 \mathrm{D}$.

Fig. 4: Distribution of cases according to best corrected visual acuity (BCVA)

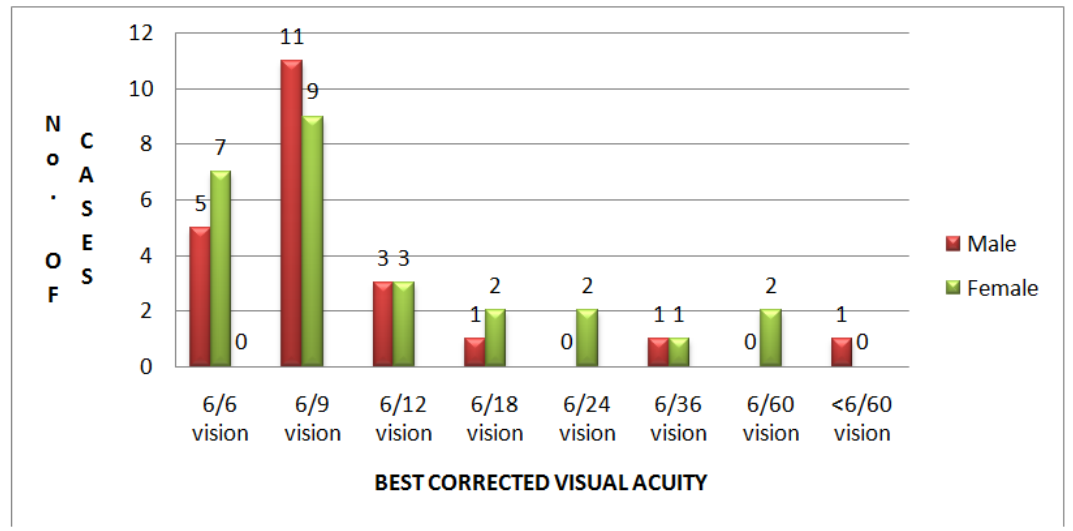

Fig 4 shows that in present study, 5 males and 7 females presented with BCVA of 6/6, 11 males and 9 females presented with BCVA of 6/9, 3 males and 3 females each presented with BCVA of 6/12, 1 male and 2 females presented with BCVA of 6/18, 2 females presented with BCVA of 6/24, 1 male and1 female each presented with BCVA of 6/36, 2 females presented with BCVA of 6/60, and 1 male presented with BCVA of $<6 / 60$.

Fig 5: Degree of deviation in Prism Diopters $(\square)$ associated with concomitant strabismus.

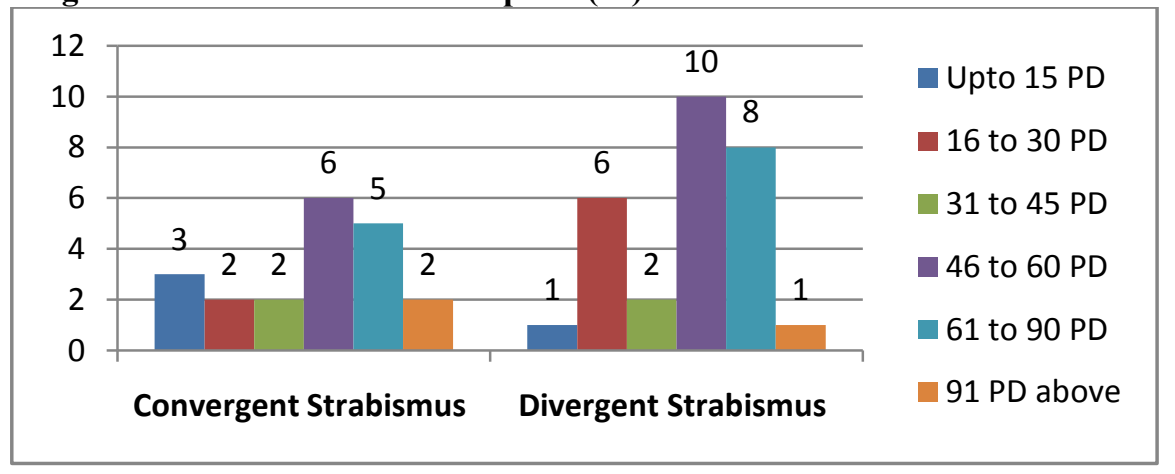

Fig. 5 shows that in this study maximum degree of deviation was recorded in 46-60 PD in both convergent and divergent squint. Male recorded 2 cases and female 4 out of 6 patients in convergent type and 5 each in divergent squint.

\section{Discussion:}

The study shows that mean age of presentation was 9.6 years. This was in contrast to findings by $\mathrm{Yu}$ $\mathrm{CBO}$ et $\mathrm{al}^{(7)}$ who retrospectively analyzed 2704 cases primary horizontal strabismus attending the Honkong Eye Hospital clinic to determine the relative prevalence of esotropia and exotropia and found the mean age of presentation to be 14.1 years (3months-91years). In their study group 53\% were female and $46.8 \%$ were male which is comparable to present study.

In the present study overall prevalence of strabismus was found to be $2.31 \%$ per per 1000 population, with a higher prevalence of exotropia (58.33\%) as compared to esotropia $(41.67 \%)$. This was comparable to the 
findings of Chia A et al ${ }^{(12)}$ who retrospectively reviewed the case file of old children presenting for the first time in the Singapore National Eye centre and KK Women and Children Hospital with horizontal concomitant strabismus and found higher prevalence of exotropia than esotropia by ratio of 7:1. They also found higher prevalence of intermittent exotropia followed by constant exotropia. In the present study 18 cases $(37.5 \%)$ had intermittent exotropia followed by intermittent esotropia 14 cases (29.17\%), and further followed by 10 cases of constant exotropia as well as 6 cases of constant esotropia.

In another study of 100 patient (upto 12 years of age) with concomitant strabismus in Kolkota, by Datta $\mathrm{D}^{(13)}$ found that esotropia (74\%) was more common than exotropia $(26 \%)$ which was in stark contrast to the present study group. She also found that esotropia was more common in males and exotropia was more common in females which were also in stark contrast to the present study in which we found more esotropes in females and exotropes in males. She also found 50\% hypermetropes, $18 \%$ myopes, $26 \%$ simple hyperopic astigmatism and $6 \%$ myopic astigmatism and no case of compound astigmatism. As in our study also all patients had associated refractive error of varying degrees,hypermetropes $33.33 \%$, myopes constitute $22.92 \%$, myopic astigmatism constituted $22.92 \%$ and hyperopic astigmatism $20.83 \%$. There was no case of compound astigmatism in the present study group as well. In her study esotropes were more commonly associated with hypermetropia than myopia and astigmatism, among exotropes they were more commonly associated with astigmatism than myopia andhypermetropia, similar trend were observed in this study also as evident from fig.1 and 2 .

The prime target of any strabismus management is to provide good visual acuity. Delayed in reporting and treatment intervention are detrimental to correction of vision ${ }^{(14)}$. In our study most of the patients had some magnitude of affected vision as evident from fig. 4 maximum patient recorded best corrected visual acuity (BCVA) of 6/9 and one male patient recorded BCVA $6 / 60$.

In the present study the degree of deviation was measured by Prism Bar Cover Test, as the prevalence of divergent strabismus was more common than convergent strabismus it is evident from fig. 5 that maximum deviation of 46-60 PD recorded in 10 cases of divergent strabismus group.

\section{Conclusion:}

Several Studies on the Caucasian population showed convergent strabismus to be more prevalent than divergent. However studies on the oriental mongoloid population shows divergent strabismus to be more prevalent.In our study divergent strabismus cases were more prevalent than convergent strabismus in ethnic Manipuris as they belong to mongoloid race and all of the patients had associated refractive error of varying degrees. Hypermetropiawas found to be more commonly associated with convergent strabismus and myopia with divergent strabismus. The overall prevalence of strabismus was found to be 2,31\% per 1000 population and also showed more prevalence in females than males.

[1] Elder SD. Ocular motility and strabismus . In: Elder SD, Wybar K, editors. System of ophthalmology Vol. VI. London: Mosby publishers; 1973: p 223-25.

[2] Kanski JJ, Bowling B. Strabismus. In:Kanski JJ, Bowling B,editors.Clinical ophthalmology,A systemic approach. $7^{\text {th }}$ edition 2011.London:elseveirs saunders;p736-772.

[3] Donnely UM, Steward NM, Hollinger M. Prevalence and outcomes of childhood visual disorders. Ophthalmic Epidemiol 2005; 12:243-50

[4] Graham PA. Epidemiology of strabismus. Br J Ophthalmol 1974: 58; 224-31.

[5] Chew E, Remalley NA, Tamboli A, Zhao J, Podger MJ, Klebanoff M. Risk factors for esotropia and exotropia. Arch Ophthal 1994:112; 1349-55

[6] Jenkins RH. Demographics. Geographical variations in the prevalence and management of exotropia. AmOrthop J 1992:42; 82-

[7] Yu CBO, Fan DSP, Wong VWY, Wong CY, Lam DSC. Changing patterns of strabismus: a decade of experience in Hong kong. Br J Ophthalmol 2002;86:854-6

[8] Lambert SR. Are there more exotropes than esotropes in Hong Kong? Br J Ophthalmol 2002; 86:835-6.

[9] Mohney BG. Common forms of childhood esotropia. Ophthalmology 2001;108:805-9.

[10] Elder SD. Ocular motility and strabismus . In: Elder SD, Wybar K, editors. System of ophthalmology Vol. VI. London: Mosby publishers; 1973: p-585.

[11] Vijayalakshmi P, Nirmalan P, Kothari MT. Pediatric ophthalmology and strabismus in India. J aapos.2004;8:18-9.

[12] Chia A, Dirani M, Chan YH, Gazzard G, Au Eong KG, Selvaraj P, Ling Y, Quah BL, Young TL, Mitchell P, Varma R, Wong TY, Saw SM. Prevalence of amblyopia and strabismus in young singaporeanchinese children. Invest Ophthalmol Vis Sci. 2010 Jul;51(7):3411-7. Epub 2010 Mar 5.

[13] Datta D. Pediatric concomitant strabismus and their relationship with different ametropias. 2011. Available at http//www.independent.academia.edu/html (Accessed Aug 20, 2012)

[14] Kikolashvil M, Shengeliia DG, Tsomia LV. Treatment of non accommodated concomitant strabismus. Georgian Med News. 2011 Feb: (191):22-6.

Images: 


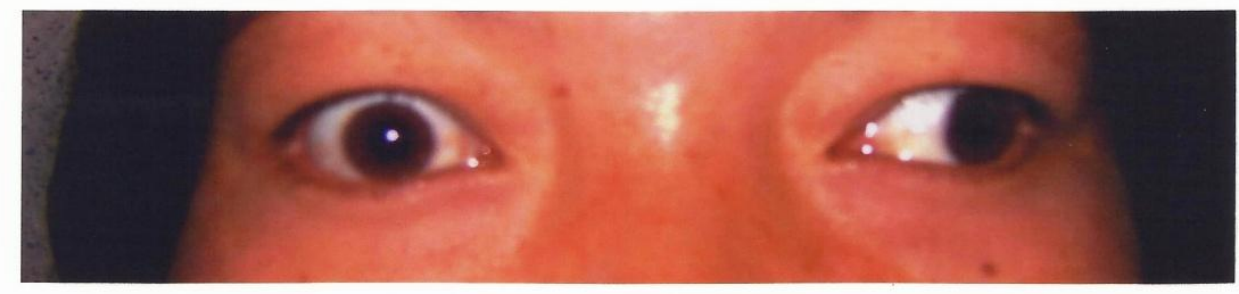

27 years old female with exotropia

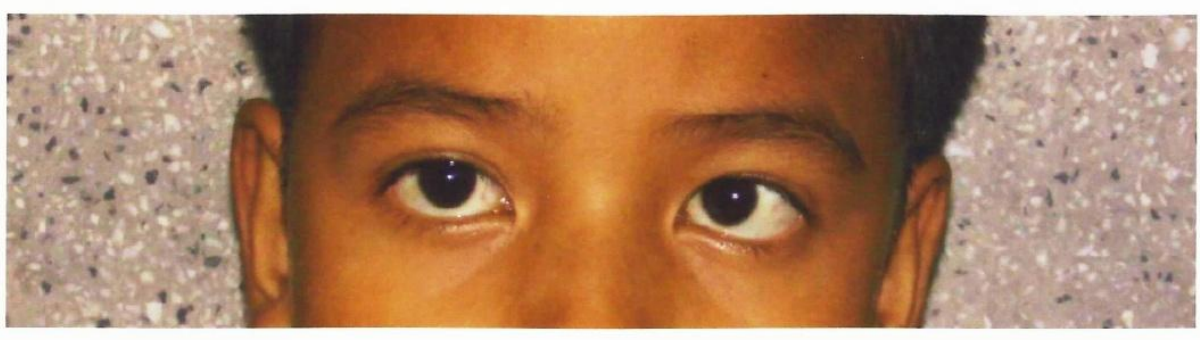

8 years old male with ' $A$ ' pattern esotropia

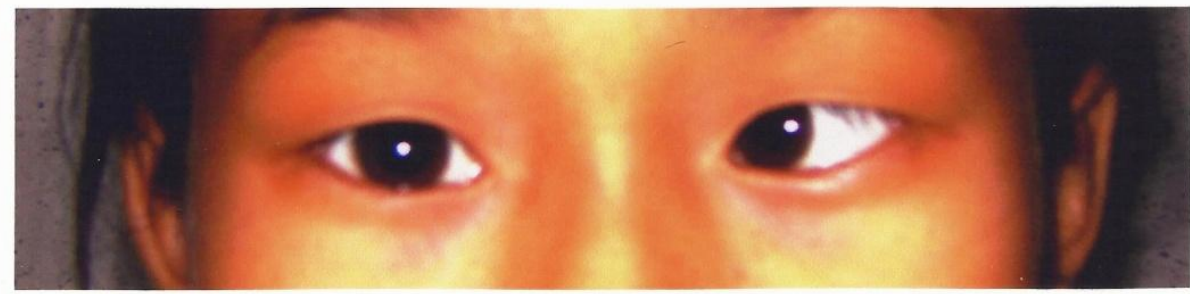

11 years old female with esotropia 